Pollack, J. B., and C. Sagan (1965), Polarization of thermal emission of Venus, Astron. J. 70, No. 2, 146.

Radhakrishnan, V., and J. A. Roberts (1961), Polarization and angular extent of the $960-\mathrm{Mc} / \mathrm{sec}$ radiation from Jupiter, Phys. Rev. Letters 4, No. 10, 493-494.

Rose, W. K., J. M. Bologna, and R. M. Sloanaker (1963), Linear polarization of the $3200-\mathrm{Mc} / \mathrm{sec}$ radiation from Saturn, Phys. Rev. Letters 10, No. 4, 123-125.

Sinton, W. M., and J. Strong (1960), Radiometric observations of Mars, Astrophys. J. 131, No. 2, 459-469.

Slee, O. B. (1964), A search for radio emission from Uranus at 11.3 cm, Astrophys. J. 140, No. 2, 823-824.

Smith, A. G., G. R. Lebo, F. N. Six, Jr., T. D. Carr, H. Bollhagen, J. May, and J. Levy (1965), Decameter-wavelength observations of Jupiter, the apparitions of 1961 and 1962, Astrophys. J. 141, No. 2, 457-477.

Soboleva, N. S., and Yu. N. Pariiskii (1964), The possibility of observing the polarization of thermal radio emission of planets, Astron. Zh. 41, No. 2, 362-365. (English transl., Soviet Astron. AJ 8, No. 2, 282-284.)

Staelin, D. H., and A. H. Barrett (1965), Radio measurements of Venus near 1-cm wavelength, Astron. J. 70, No. 5, 330-331.

Thornton, D. D. and W. J. Welch (1963), $8.35 \mathrm{~mm}$ radiation from Jupiter, Icarus 2, No. 3, 228-232.

Tolbert, C. W., and A. W. Straiton (1964a), 35-Gc/s, 70-Gc/s and 94-Gc/s Cytherean radiation, Nature 204, No. 4965, 1242-1245.

Tolbert, C. W., and A. W. Straiton (1964b), An investigation of 35 Gc, $70 \mathrm{Gc}$, and $94 \mathrm{Gc}$ Cytherean radiation, Electrical Engineering Research Laboratory, University of Texas, Report No. I-02, October 15.

Troitsky, V. S. (1954), Theory of lunar radio emission, Astron. Zh. 31, No. 6, 511-528.

Vetukhnovskaya, Yu. N., A. D. Kuzmin, B. G. Kutuza, B. Ya. Losovskii, and A. E. Salomonovich (1963), Measurement of radio emission from the night side of Venus in centimeter wavelength range, Izv. Vysshikh Uchebn. Zavedenii, Radiofiz. 6, 1054-1056.

Walker, J. C. G. (1961), The thermal heat budget of Mercury, Astrophys. J. 133, No. 1, 274-280.

Welch, W. J., and D. D. Thornton (1965), Recent planetary observations at wavelengths near $1 \mathrm{~cm}$, Astron. J. 70, No. 2, 149-150.

\section{Additional Related Reference}

Basharinov, A. E., Yu. N. Vetukhnovskaya, A. D. Kuzmin, B. G. Kutuza, and A. W. Salomonovich (1964), Measurements of the brightness temperature of Venus at $8 \mathrm{~mm}$, Astron. Zh. 41, No. 4, 707-710. (English transl., Soviet Astron. AJ 8, No. 4, $563-565,1965$.

\section{Discussion Following Barrett's Paper}

D. O. Muhleman: Have the data points in the planetary spectra you presented been corrected to the same phase angle?

Alan H. Barrett: No.

D. O. Muhleman: Wouldn't such a correction decrease the scatter in the points?

Alan H. Barrett: Other uncertainties in the data are certainly larger than the displacements in the points caused by phase effect.

$J$. A. Roberts: Is the radar rotation period of Mercury sufficiently great to explain the high temperature observed on the dark side of the planet?

Alan H. Barrett: I have not made these calculations.

$F$. D. Drake: If the surface of Mercury is like that of the Moon, then despite the somewhat greater rotation period we would expect the radio emission behavior to be very much like that of the Moon. As is well known, at the wavelengths at which Mercury has been observed, the dark side of the Moon is nearly as bright as the bright side, and so we would expect the same behavior of Mercury.

J. H. Thomson: R. D. Davies has now determined that the apparently very high brightness temperatures of Mars at 21-cm wavelength observed at Jodrell Bank in 1963 were seriously affected by a confusing cosmic radio source, with the result that the Martian brightness temperature appeared very much higher than it actually was. After correction for this confusing source, the equivalent blackbody disk temperature for Mars at the 21-cm wavelength in 1963 was 320 $\pm 95{ }^{\circ} \mathrm{K}$. Similar measurements during the 1965 opposition produced an equivalent blackbody disk temperature of $225^{\circ} \mathrm{K}$.

\title{
Mars and Venus at 70-cm Wavelength
}

\author{
H. E. Hardebeck
}

Center for Radiophysics and Space Research, Cornell University, Ithaca, N.Y.

Observations of Venus and Mars at a frequency of $430 \mathrm{Mc} / \mathrm{s}$ have been made with the Arecibo telescope. An observing technique was used in which the source was observed, and some days later, when the planet had left its previous position, the position was reobserved to determine the flux produced by the background radio sources. The equivalent blackbody temperature measured for Venus at $430 \mathrm{Mc} / \mathrm{s}$ was $518 \pm 40^{\circ} \mathrm{K}$. The upper limit on its flux density at $1 \mathrm{~A} . \mathrm{U}$. was 0.05 $\times 10^{-26} \mathrm{MKS}$ units at $195 \mathrm{Mc} / \mathrm{s}$. The upper limit at $430 \mathrm{Mc} / \mathrm{s}$ was $0.024 \times 10^{-26} \mathrm{MKS}$ units.

(Paper 69D12-594) 